\title{
Study on the Successful Elements of the Fantasy Network Novel Coiling Dragon's International Communication
}

\author{
Qi Chen \\ Foreign Language College \\ Chengdu University of Information Technology \\ Chengdu, China
}

\begin{abstract}
Chinese fantasy network works have been loved by ordinary foreign readers in recent years, which supplies a true and effective channel to touch the common people in their daily life and help them understand China and Chinese culture in a natural way. It is significant to China which has always sought to spread the culture to the outside world. Coiling Dragon has been praised by ordinary foreign readers as the "entry level" works if a foreigner wants to read Chinese fantasy network novels. It adopts the mode all the people appreciate, in which nobody can turn his or her big dream into reality by his or her own effort. It borrows the framework from the western fantasy novels, which reduces the difficulty of foreign readers' understanding. The content of the novel includes the elements of the traditional Chinese culture, and at the same time, its translation also pays attention to retaining the Chinese cultural features, both of which strengthen the novelty of the foreign readers. To some degree, the success of this novel in international communication has some reference value to the selection of network novels that will be translated into Engligh in the future.
\end{abstract}

Keywords - coiling dragon; successful elements; international communication

\section{INTRODUCTION}

The output of Chinese culture is one of the hottest topics in recent years. Not only the state has invested a lot of manpower and material resources, but also the scholars have made many related books. It is undeniable that these efforts have achieved good results, but there are still some shortcomings. For example, to the translation work of the Chinese classics, most of the readers are only Chinese learners and scholars who study China. Ordinary foreign readers are difficult to be attracted by them. Until 2016, with the successful international communication of Chinese network novels, China has found a way to make up the short board for the dissemination of literature. The main bodies of Chinese network novels' readers are the ordinary in foreign countries. When Zhou Zhixiong summed up the inadequacies of the study of Chinese network literature, it was mentioned at first that network literature is more a literary phenomenon than a literary case.[1] This shows that China's case studies on network literature are still lacking. Coiling Dragon is the first Chinese fantasy network literature read by a number of ordinary foreign readers, especially the western readers, and has been recommended by many of them as the "entry level" works of reading Chinese fantasy network literature. As a case of network literature, it is valuable to study its successful way of international communication.

\section{SUCCESSFUL ELEMENTS}

\section{A. Framework Borrowing from Western Fantasy Novels}

The theory of Cultural Proximity is first proposed by Joseph Straubhaar in 1991. It means that based on the familiarity in the local culture, language, customs and so on, the audience is more inclined to accept the program content that is close to their culture, language and customs. And when all other conditions are equal, the audience will prefer the content similar to their national culture.[2]

Chinese is considered as one of the most difficult languages in the world. And there are many great differences in the way of thinking between China and the west. Therefore, many foreigners in western countries feel difficult to understand the Chinese characters and literature works, and are easy to give up their reading. Even the martial arts novels, which are deemed to be very popular and easy to understand by many Chinese readers, are very difficult to the ordinary western readers, for the great differences in culture and language. In fact, the translation of Chinese martial arts novels has failed many translators. When he initially began to do his translation, the wuxiaworld website stationmaster did not translate the works of Chinese network literature, but one of the martial arts masterpieces of Mr. Jin Yong. However, he abandoned at last. The first reason is the difficulty of translation. He recalled that he once thought about how to translate a sentence in Mr. Jin Yong's novel for three hours.[3] The second reason is he found that it was very tough to read the translation works for the foreign readers who did not know the long history and profound cultural connotation of China. So it is a big problem to attract the ordinary in western countires to read Chinese literature.

But the appearance of Chinese network novels begins to solve this problem. Chinese network literature, especially Chinese fantasy network novel is loved by the ordinary foreign readers. Coiling Dragon is an outstanding representative of them. The two Chinese words of Qi Huan comes from the 
English word "fantasy". Western fantasy novels have a long history. More than two thousand years ago, there have been works of fantasy elements, and the source of fantasy novels can be traced back to the Greek, Rome and Nordic myths. Nowadays, there are several branches of western fantasy novels, one of which is related to magic. After reading it, people can see that the whole novel is similar to those European and American novels in many ways. The hero, named Linlei Buluke, is translated into Linley Baruch in the English version of the wuxiaworld website. The name is a typical westerner's name and is very friendly to Westerners. The status system of people is also known by western people, such as Marquis, Earl, etc., and even the whole social organization has the elements coming from western culture in the novel. Coiling Dragon is based on magic, just as mentioned before. The magic world it depicts contains many magic, devil and other elements. From the name to the magic system described, the whole novel is influenced by western fantasy novels. Looking at the content of the novel, it can be found that like the western fantasy novels, the novel also has the unreal framework of the world, the mysterious evil forces, the inteligent unhuman beings, and the religious system from the reality and out of the reality. In a sense, Coiling Dragon itself is the imitation of western fantasy novels and is a representative of this kind of novels in China's popularization. Fantasy novels are not new to foreign readers. In the world, fantasy novels and movies have been widely accepted by the public. That's to say, it is similar to the national culture of the ordinary foreign readers in western countries. According to the theory of Cultural Proximity, the ordinary foreign readers will prefer Coiling Dragon, whose content is full of western fantasy elements and similar to their own national culture. The novel is easier for them to understand and enjoy than those traditional Chinese classics.

\section{B. Chinese Cultural Elements' Appropriate Integration}

This part includes two aspects: one is the content of the novel itself and the other is the translator's translation of the novel.

The content of Coiling Dragon includes some Chinese cultural elements. As mentioned in the previous part, it reduces the difficulty of understanding for the ordinary foreign readers by borrowing the typical elements from western fantasy novels, so that they are willing to start trying to read. In the course of reading, in addition to the fantasy fiction elements familiar to ordinary foreign readers, the Chinese fantasy network novel is full of many things they are not familiar with, making them feel fresh and strange. For example, the novel absorbs Chinese local culture and legends, as well as the martial arts elements that are exported from the best-selling book system in Hong Kong and Taiwan, so that it has a different sense of novelty in the eyes of foreign readers. In Coiling Dragon, there are the elements of western fantasy novels, such as magic spells, while there are also the elements of traditional Chinese culture, such as the magical and powerful swords, knives, and skills in martial arts. The familiarity is mixed with strange new feelings, which makes the novel have different glamour compared with western fantasy novels.
From the perspective of the translation of Coiling Dragon, the translator pays attention to the preservation of Chinese cultural characteristics. The translation of Chinese "Long" shows this point clearly. It is translated as "dragon" directly in the novel. As we all know, dragon has different images in Chinese and western traditional culture. The origin of dragon can be traced back to eight thousand years ago in China. It used to be a tool for ancient ancestors to communicate with gods. Dragon is the symbol of honor, noble and imperial power. The supreme ruler of ancient times always connected himself with the dragon. Dragon is the private privilege of the rulers. All aspects of the ruler's life are related to dragon in China. For example, the emperor's chair was known as the "dragon chair" in ancient times. At the same time, dragon is also a symbol of success. There is an idiom in China called "carps jump into dragon's door", which represents the carp (a nobody) finally achieves its success and turns into dragon. Dragon is a unique cultural condensation and accumulation of Chinese people. It has been deeply rooted in the subconscious of every Chinese. Dragon is the most noble and beautiful image of China in thousands of years.

However, dragon is evil and fierce in the eyes of westerners A remarkable negative image can be found out from the two origins of western culture. In Greek mythology, the gods battle with the villain dragon giant, who is ugly and defeated. In the Bible, Satan is called the great dragon. The novel's title is Coiling Dragon, which is translated by literal translation. When the ordinary western readers read the word Dragon, there will be negative feelings in the subconscious minds. But in fact, when they finish their reading, they could find different images of this word. There are dragons with a negative image in the novel, such as the magical beast Velocidragon in the eighth chapter. However, there are many positive images of dragon. After the protagonist Linley Baruch becomes a Dragonblood warrior, whose shape shows the characteristics of a dragon. In the novel, the positive image of dragon corresponds to Chinese traditional culture, which makes foreign readers have different imagination about it. Lai Jingping, the stationmaster of the wuxiaworld website, also pointed out in a media interview that compared with western works, Chinese fantasy and fairy tale novels are based on a wide field constructed by the profound Chinese culture, history and mythology.[4] There are many other contents in Coiling Dragon, such as Dao, the theory of five elements, etc., belongs to the representative traditional Chinese culture. To those Western netizens who know them for the first time, they are fresh and interesting.

\section{Human Commonness-Heroic Dream of the Ordinary}

The current situation shows that the reason why the ordinary foreigners love to read Chinese network novels is almost the same as those domestic fans. Unlike the past elite culture export mode, the most powerful force of overseas dissemination of Chinese network literature is to try to grasp the pleasant feelings of the ordinary foreign readers. The novel Coiling Dragon is a typical representative, which follows the most traditional nonentity's successful novel mode. The protagonist of the novel was born in a declining family. When Linley Baruch was a child, his mother disappeared. When he was a teenager, his father was killed. He became a nobody. But 
the nonentity had a big dream. He had a hard training in martial arts, hoping to be able to avenge and rejuvenate his family one day. Although the process full of many hardships and efforts, the protagonist finally achieve his ideal. This is also a typical routine of Chinese fantasy network novels, which makes Chinese readers feel happy. Ordinary western readers seldom read such works before. It is easy to make them feel fresh, interesting and happy, too. The model of "a nobody becoming a very important person in the end by his or her own effort" in Chinese network literature is quite universal in the world. Maybe some people think such works are not deep enough. But it can satisfy the common desire of different people at home and abroad, and make people feel the sense of achievement and the joy when a big dream comes true in an ordinary person's life. In addition, He Yi believes that compared with western novels, Chinese novels are used to express the inner psychology of the character by his or her own action for a long time, when an author tries to shape the character, and there are few long psychoanalytic descriptions of the character in a western novel.[5] The characteristic of focusing on action in Chinese traditional novels are well carried out in Chinese fantasy network novels. The psychological description of the characters in the novel is always integrated with the action, which is embodied in the powerful action of the hero. And such kind of powerful action further deepens the pleasure of readers. Kong Xuesong, the founder of the Gravity Tales website, has also said that he have never seen such a role who can gain power quickly and achieve their desires. He thinks these kinds of fantasy network novels are greatly attractive to readers. [6]

\section{CONCLUSION}

After years of development, fantasy network novels in China have been increasingly popular among ordinary foreign readers in the last three or four years. Li Jingze, a literary critic, believes that the export of Chinese culture depended on the mainstream channels, such as literary awards, book exhibitions, film festivals, and copyright output in the past, but the spead of Chinese network novels this time really means that Chinese popular culture has come into the daily life of the common people of Europe and the United States for the first time.[7] On the basis of the framework of western fantasy novels, the novel Coiling Dragon retains the unique traditional culture of China at the same time. And its translation also pays attention to the preservation of Chinese unique culture. As far as its content is concerned, the novel highlights the action power of the protagonist and meets the heroic dream of nobody in different people's mind. All of them make ordinary foreign readers feel fresh, interesting and pleasant. That is why it is widely accepted. The success of this novel in international communication gives some clues on how to select suitable network novels that will be translated into English in the future.

However, the novel is too close to the western fantasy mode, and Chinese elements are relatively scarce. It will help the ordinary foreign readers touching China and Chinese culture for the first time to understand the culture of great difference naturally and easily. From the perspective of cultural communication, conscious translation of some network novels with more traditional Chinese cultural features can be done in the future in order to meet the needs of foreign readers who wants to learn more about China and Chinese culture.

\section{REFERENCES}

[1] Zhou ZhiXiong, "The development and research status of network literature", Journal of Shenyang University, pp. 63-67, 2010(2).

[2] Yin Jun, "Cross media management", Chengdu: Sichuan University Press, pp. 206-207, 2006.

[3] http://www.chinawriter.com.cn/n1/2017/0207/c404023-29063771.html

[4] http://www.sohu.com/a/159805081_552907

[5] He Yi, "Comparison between Chinese and western culture", Beijing: Metallurgical industry press, pp. 181, 2010.

[6] http://www.china.com.cn/guoqing/2017-05/10/content_40780975.htm

[7] http://www.chinanews.com/cul/2016/12-26/8104774.shtml 